\title{
Por que o termo feminicídio incomoda tanto? um estudo de caso de comentários de posts da página do Facebook do Jornal $O$ Globo*
}

\author{
Gabriella Hauber**
}

\begin{abstract}
Resumo
O objetivo deste artigo é analisar a forma como cidadãos ordinários entendem e discutem a violência letal contra mulheres e a relação dessas discussões com o enquadramento que diferentes notícias dão a esse tipo de ocorrência. Adotamos a análise de conteúdo como estratégica metodológica para analisar comentários da página do Facebook do jornal O Globo sobre três casos de assassinatos contra a mulher, com enquadramentos jornalísticos distintos. Observamos que o termo feminicídio pode incomodar mais os cidadãos que comentam do que os casos de violência em si.
\end{abstract}

Palavras-chave: Feminicídio, Violência Contra a Mulher, Conversação Política, Deliberação Online, Facebook.

* Recebido em 11 de novembro de 2018, aceito em 01 de outubro de 2019. O presente trabalho foi realizado com apoio da Coordenação de Aperfeiçoamento de Pessoal de Nível Superior - Brasil (CAPES) - Código de Financiamento 001.

** Doutoranda do Programa de Pós-Graduação em Comunicação Social da UFMG, Belo Horizonte, MG, Brasil. gabihauber@gmail.com / https://orcid.org/0000-0001-6848-2518 
cadernos pagu (59), 2020e205913 Por que o termo feminicídio incomoda tanto?

Why is the Term Femicide so Disturbing? A case study of comments posted to the Facebook page of the newspaper $\mathrm{O}$ Globo

\begin{abstract}
The purpose of this article is to analyze how ordinary citizens understand and discuss lethal violence against women and the relation of these discussions to the framing that news articles give to this type of occurrence. Content analysis was the methodological strategy used to analyze comments posted on $\mathrm{O}$ Globo's Facebook page in response to news about three murders of women that had different journalistic framings. We note that the term femicide may disturb more people who comment than the murders per se.
\end{abstract}

Keywords: Femicide, Violence against Women, Political Conversation, Online Deliberation, Facebook. 


\section{Introdução}

O objetivo deste artigo é analisar a deliberação online sobre o feminicídio. Mais especificamente, a forma como cidadãos ordinários entendem e discutem a violência letal contra mulheres e a relação dessas discussões com o enquadramento que diferentes notícias dão a esse tipo de ocorrência. A violência contra a mulher é pauta recorrente de movimentos feministas. Nos anos 1960 e 1970, em países como França e Estados Unidos, a discussão estava relacionada ao direito ao corpo, enquanto, no Brasil, a questão foi mais fortemente tematizada após o assassinato de Ângela Diniz e a posterior absolvição do assassino, conhecido como Doca Street, em 1976 (Blay, 2003; Sarmento, 2014). De lá para cá, é crescente o interesse por discussões envolvendo a violência contra a mulher na América Latina.

Parte desses estudos busca analisar a forma com que a violência contra a mulher é enquadrada e abordada pelos media (Bandeira, Vieira e Campos, 2017; Angelico et. al, 2014; Magalhães-Dias e Lobo, 2016; Perulero, 2014; Sarmento, 2014), a representação das mulheres nos media (Biroli, 2010; Miguel e Biroli, 2009) ou discutem a violência contra a mulher nas sociedades de maneira geral e no sistema de justiça (Machado e Elias, 2018; Pasinato, 2011). No entanto, ainda são raros os estudos que analisam o debate público sobre o feminicídio, sobretudo, aquele realizado por cidadãos ordinários. Na tentativa de contribuir para suprir essa lacuna, este artigo busca analisar a deliberação online sobre o feminicídio. Para isso, iremos comparar os comentários de três posts da página do Facebook do jornal O Globo: a) um que caracteriza explicitamente um assassinato como feminicídio b) outro que tem como foco uma reportagem geral sobre o feminicídio; c) outro sobre a notícia de um caso específico de assassinato de uma mulher, mas que não faz referência explícita ao termo feminicídio. Pretendemos verificar se há diferenças na conversação online quando o assunto é explicitamente tratado como feminicídio e quando o foco é um assassinato tratado como "um crime comum". 
cadernos pagu (59), 2020e205913 Por que o termo feminicídio incomoda tanto?

Ao contrário de outros estudos sobre deliberação online, não iremos verificar a deliberatividade das conversações em redes sociais, apontando em que medida elas se aproximam dos ideais normativos da deliberação (Barros e Carreiro, 2017; Mendonça e Amaral, 2017; Mitozo e Marques, 2017; Steiner et al. 2004; StromerGalley, 2007). Nosso objetivo é, a partir dos comentários na página de Facebook do jornal $\mathrm{O}$ Globo, analisar como cidadãos ordinários discutem a violência contra a mulher e como se posicionam diante do feminicídio. Estamos mais interessadas no conteúdo dos atos de fala (comentários) e sua relação com a notícia que os origina do que nos procedimentos das trocas argumentativas. Para isso, formulamos as seguintes questões:

1) Como a violência contra a mulher é enquadrada pelos usuários da página do jornal O Globo no Facebook? Os usuários estabelecem uma correlação entre o crime e o fato de a vítima ser mulher (referência explícita ao feminicídio)?

2) Existem diferenças nos comentários quando o post do jornal que desencadeou a discussão faz referência a um caso de violência específico daqueles comentários feitos quando o texto se propõe a uma discussão mais geral sobre o feminicídio?

Para respondê-los, este artigo se estrutura da seguinte maneira: em um primeiro momento, faremos uma breve discussão sobre media e feminicídio e, posteriormente, sobre Teoria Deliberativa $e$ as críticas feministas à corrente. Em seguida, descreveremos a metodologia adotada. Por fim, apresentaremos os resultados e a discussão dos principais achados.

\section{Mulheres e feminicídio nos media}

A legislação brasileira que pretende promover a igualdade de gênero no Brasil ainda é recente. Até a sanção da Lei do Feminicídio (Lei $\left.\mathrm{N}^{\circ} 13.104 / 2015\right)$ pela então presidenta Dilma Rousseff, em 2015, o principal instrumento legal de combate à 
violência contra a mulher era a Lei Maria da Penha (Lei $\mathrm{N}^{\circ}$ 11.340/2006), que "cria mecanismos para coibir a violência doméstica e familiar contra a mulher" -- violência essa entendida como "qualquer ação ou omissão baseada no gênero que the cause morte, lesão, sofrimento físico, sexual ou psicológico e dano moral ou patrimonial". Nesse contexto, se inserem diferentes formas de violência: física, psicológica, sexual, patrimonial $e$ moral, com previsão de prisão do agressor. Além disso, a Lei Maria da Penha também prevê assistência à mulher vítima de violência e medidas protetivas. Uma das limitações da Lei $\mathrm{N}^{\circ}$ 11.340/2006 é restringir a violência ao ambiente familiar, deixando de lado o espaço público, extremamente machista. Apesar de ser considerada um importante avanço pela Organização das Nações Unidas (ONU), a Lei Maria da Penha não conseguiu reduzir significativamente os casos de violência contra a mulher no Brasil.

As notificações de violência contra esse público vem aumentando, o que mostra uma fragilidade do cumprimento da legislação. De acordo com o Mapa da Violência 2015, o Brasil ocupa $\circ 5^{\circ}$ lugar no ranking de países com maior índice de feminicídio. Dados do DataFolha, divulgados em março de 2017, revelam que uma em cada três mulheres ouvidas pela pesquisa havia sofrido algum tipo de violência: $22 \%$ sofreram ofensa em 2016, o que representaria um total de 12 milhões de mulheres. Além disso, $10 \%$ das mulheres sofreram ameaça de violência física, $8 \%$ sofreram ofensa sexual, $4 \%$ receberam ameaça com faca ou arma de fogo, e $3 \%$ sofreram espancamento ou tentativa de estrangulamento e $1 \%$ levou, pelo menos, um tiro.

As políticas de enfrentamento à violência contra a mulher no Brasil foram criadas a partir de lutas dos movimentos feministas $e$ pela presença de mulheres nos espaços políticos formais, que se intensificaram a partir da década de 1970 (Andrade e Matos, 2017; Blay, 2003; Gomes, 2018). Antes disso, o argumento de legítima defesa da honra era utilizado para inocentar homens envolvidos em casos de violência contra a mulher. Um dos principais argumentos para que o feminicídio tivesse uma tipificação específica no código penal brasileiro é o de dar visibilidade e 
cadernos pagu (59), 2020e205913 Por que o termo feminicídio incomoda tanto?

quantificar de maneira mais eficiente o assassinato de mulheres pelo simples fato de serem mulheres - ou seja, nomear a especificidade desse crime é uma forma também de enfrentar a naturalização das opressões e da violência de gênero. A prática de feminicídio seria não somente o resultado dessas opressões, mas também uma forma de manutenção das desigualdades entre homens e mulheres e nomeá-la seria um passo importante para enfrentar essa perpetuação (Pasinato, 2011).

Gomes (2018) aponta três principais vertentes de análise da violência letal de mulheres: a) genérica, que entende o feminicídio como qualquer morte violenta de mulheres relacionada à desigualdade de gênero, como o assassinato e a morte decorrente do aborto; b) específica, relacionada ao assassinato de mulheres enquanto um tipo de assassinato que possui singularidades que o caracterizam; e c) judicializadora, que parte de um diálogo entre o feminismo e o direito penal em um debate sobre a judicialização da violência de gênero. Para a autora, tipificar um assassinato de mulher como feminicídio é fundamental para "visibilizar a letalidade e a não acidentalidade da violência de gênero" (Gomes, 2018:3). Na Lei do Feminicídio brasileira, esse tipo específico de violência é caracterizado pela motivação do crime, ou seja, quando a mulher é assassinada "por razões da condição de sexo feminino", envolvendo "violência doméstica e familiar" e "menosprezo ou discriminação à condição de mulher".

Machado e Elias (2018) não acreditam que a criminalização por si só resolva o problema da violência contra a mulher, mas defendem que a judicialização do feminicídio é importante tanto simbólica quanto politicamente. "A constituição de um tipo penal derivado pode contribuir para gerar novas estatísticas, novos discursos jurídicos, mudanças no imaginário cultural, novas demandas por igualdade. Constitui-se, também, na tradução política de uma vivência das mulheres - política na medida em que vai para a esfera pública, transformando-se em lei" (Machado e Elias, 2018:297).

Os media também possuem um papel fundamental para dar visibilidade e levar questões importantes para uma discussão na 
esfera pública (Maia, 2012). Muitos desses crimes violentos ocupam periodicamente o noticiário brasileiro. E a maneira como o tema ganha visibilidade nos media pode ser uma forma tanto de contribuir para o enfrentamento da violência quanto de reprodução de desigualdades de gênero e estereótipos presentes na sociedade.

Em primeiro lugar, a mídia não produz os estereótipos, mas atua no sentido de reforçá-los ou confrontá-los. Pode, mesmo, mobilizar esses estereótipos de maneira localizada, enquanto os questiona em padrões discursivos que adquirem estabilidade relativa em um dado momento ou, ao contrário, pode apresentar posições críticas em circunstâncias específicas enquanto mantém, em ampla medida, uma relação estreita com as convenções e papeis socialmente estruturados (Biroli, 2010:59).

Flávia Biroli (2010), ao analisar a cobertura do noticiário político sobre três mulheres (Dilma Rousseff, Marta Suplicy e Heloísa Helena), discute que há pouco espaço nessa seção destinado às mulheres que, quando aparecem, têm a presença marcada por estereótipos de gênero, como em notícias relacionadas à família, ao corpo e aos afetos e cuidados. Esse tipo de comportamento dos media é um indicativo de naturalização dos papeis socialmente demarcados para homens e mulheres. A seletividade temática caminha, assim, junto com uma visibilidade também seletiva, em que as fronteiras entre ideias e corpo, entre razão e afeto e, de maneira mais ampla, entre público e privado confirmam "pertencimentos" sociais diversos" (Biroli, 2010:66).

As notícias que abordam especificamente a violência contra a mulher, raramente, contribuem para algum tipo de enfrentamento a esse tipo específico de violência. Apesar de todos os dados indicarem a alta frequência de feminicídio, por exemplo, os casos ainda são tratados de maneira isolada, sem contextualização (Wozniak e Mccloskey, 2010). Mostrar que os casos não são isolados e sim recorrentes e um reflexo de uma sociedade machista e patriarcal, que perpetua a desigualdade entre homens 
cadernos pagu (59), 2020e205913 Por que o termo feminicídio incomoda tanto?

e mulheres, seria uma maneira de os media problematizarem a recorrência de casos de violência contra a mulher e, de certa forma, educar o público sobre a questão $e$ fomentar um entendimento mais preciso sobre o problema (Magalhães-Dias e Lobo, 2016; Segato, 2006; Wozniak e Mccloskey, 2010). Segato (2006) também aborda a importância da politização do feminicídio em sua especificidade, ao tratá-lo não como mais um homicídio, para reforçar que eles são resultados de um sistema de poder e não casos isolados. "Era necessário demarcar, diante dos media, o universo dos crimes do patriarcado $e$ introduzir no senso comum a ideia de que há crimes cujo pleno significado só pode ser vislumbrado quando pensado no contexto do poder patriarcal" (Segato, 2006: 4, tradução nossa ${ }^{1}$ ). Nesse sentido, a sociedade civil teria um papel fundamental de pressionar os media a abordarem o feminicídio de maneira contextual. Um bom exemplo disso é o movimento \#Niunaamenos, na Argentina, em 2016, que conseguiu pautar uma campanha sobre a temática nos jornais, que passaram a abordar o feminicídio como um problema da sociedade e não mais algo particular/doméstico (Luengo, 2017).

Além da contextualização, a partir, por exemplo, da exposição de dados estatísticos sobre violência contra a mulher, outro ponto importante é os media nomearem os assassinatos de mulheres por razão de gênero como feminicídio e não como homicídio. Nomear o feminicídio não é apenas trocar um vocábulo por outro, mas uma forma de dar visibilidade e localizar a violência de gênero, além de compreender esse tipo de crime como um fenômeno fortemente presente na estrutura social brasileira (Gomes, 2018; Marcuello-Servós et al, 2016; Wozniak e Mccloskey, 2010).

\footnotetext{
${ }^{1}$ No original: "Era necesario demarcar, frente a los medios de comunicación, el universo de los crímenes del patriarcado e introducir en el sentido común la idea de que hay crímenes cuyo sentido pleno solamente puede ser vislumbrado cuando pensados en el contexto del poder patriarcal" (Segato, 2006).
} 


\section{Deliberação online e críticas feministas}

Como iremos analisar comentários no Facebook, é importante fazermos uma breve discussão sobre conversação e deliberação online. Ressaltamos novamente que não vamos analisar em que medida ocorre deliberação em ambientes online e tampouco a qualidade dessas discussões, nosso interesse é investigar como cidadãos ordinários discutem a violência contra a mulher. Acreditamos que há momentos deliberativos em conversações, em que, por exemplo, cidadãos engajam com os argumentos convocados, ao mesmo tempo em que não é possível esperar que eles estejam constantemente em cooperação (Goodin, 2005). Além disso, acreditamos que analisar a conversação online a partir de critérios deliberativos, como respeito e justificação, pode revelar nuances sobre a formulação $e$ a defesa de preferências dos cidadãos sobre temas de interesse público, como a violência, mais especificamente, a violência letal contra a mulher.

Nas perspectivas clássicas da teoria deliberativa, a resolução dos conflitos e uma possível tomada de decisão poderiam se dar por meio de trocas argumentativas mutuamente aceitáveis $e$ justificáveis e que levariam a um entendimento final. Cohen (2009) e Habermas (2011) discutem procedimentos ideais para que a deliberação aconteça de maneira mais justa, como igualdade, racionalidade argumentativa $e$ inclusividade. Tais procedimentos, assim como o próprio conceito de esfera pública proposto por Habermas, foram alvos de muitas críticas, sobretudo por teóricas feministas. Fraser (1990) argumenta que a esfera pública conceitualizada por Habermas em "Mudança Estrutural da Esfera Pública" reproduz exclusões e que os processos deliberativos favoreceriam, principalmente, a presença masculina. A autora defende a existência de outras esferas e contrapúblicos, o que seria considerado por Habermas (2011 [1992]) posteriormente.

Apesar de a inclusividade ser um dos ideais normativos da deliberação e de trabalhar bem próxima à vertente, Iris Young (1999) também direciona críticas a Habermas, apontando que a 
cadernos pagu (59), 2020e205913 Por que o termo feminicídio incomoda tanto?

deliberação tenderia a ser mais exclusiva do que inclusiva, uma vez que privilegiaria uma parcela da sociedade capaz de argumentar de maneira estruturada. Para ela, um modelo político justo deve ser baseado em uma discussão pública que inclua as diferentes perspectivas dos grupos sociais da sociedade. Nesse sentido, ela defende que diferentes formas comunicativas, não somente a racional/argumentativa, deveriam ser levadas em consideração para que a discussão seja justa. Young (1999) também apresenta ressalvas em relação ao ideal de bem comum presente em formulações deliberativas clássicas. Ela não vê problemas em os participantes defenderem seus próprios interesses, desde que sejam capazes de justificar as suas propostas.

Essas e outras críticas ao modelo deliberativo habermasiano buscaram ser incorporadas por teóricos deliberacionistas em diferentes abordagens da corrente, que se propõe, entre outros, incorporar nos processos deliberativos diferentes formas de comunicação, como testemunhos, emoções e humor (Black, 2009; Maia, 2012; Polletta e Lee, 2006; Steiner, 2012; Steiner et al., 2017). Nesse contexto, o papel dos media na deliberação ganha força, sobretudo, enquanto uma arena deliberativa que dá visibilidade a diferentes posicionamentos, sendo também insumos para as conversações cotidianas. Neste artigo, teremos como foco as mídias digitais digitais enquanto arenas de conversação, com momentos deliberativos, que tornam possivel a conversação política em larga escala entre cidadãos ordinários sobre temas sensiveis a eles.

\section{Media online}

O ambiente digital tem despertado crescente interesse entre os teóricos deliberacionistas. Apesar de suas mais variadas contradições, a internet tem sido vista como um importante fórum expandido de participação, abrigando diferentes visões sobre variados temas (Dahlgren, 2005; Bohman, 2004; Papacharissi, 2004; Stromer-Galley, Wichowski, 2011), além de não possuir barreiras geográficas. Bohman (2004) chega a falar em uma esfera pública 
transnacional, como um espaço ilimitado para a interação comunicativa, sem os custos dos meios de comunicação de massa. Porém, por mais que amplie a audiência, a deliberação na internet enfrenta alguns desafios. Ela pode aumentar a interação, mas sem preservar as características do diálogo, além de poder reproduzir e até mesmo amplificar as coerções e as desigualdades existentes nas relações face-a-face (Gervais, 2015; Sunstein, 2001). Em um tema sensível, como a violência contra a mulher, não é raro encontrar comentários em fóruns de discussão que reproduzam essas assimetrias das interações off-line.

As redes sociais, de certa forma, abrigam parte das conversações cotidianas tão importantes para a deliberação. Tais conversas são, na maioria das vezes, espontâneas, informais e não constrangidas por procedimentos formais, como preconizado para a deliberação formal - embora, no caso das conversações online, possa haver constrangimentos vindos das plataformas nas quais ocorrem, como a presença de moderações (Maia et al., 2015). De toda forma, entendemos que as conversações informais são fundamentais para o engajamento cívico dos cidadãos e para a formulação e defesa de preferências sobre temas de interesse público. Nesses momentos e espaços, os cidadãos se sentem mais à vontade para expor suas opiniões e perspectivas. Neste artigo, estamos interessadas exatamente em investigar como os diferentes posicionamentos sobre a violência contra a mulher são defendidos $e$ expostos nas conversas online e o que eles revelam sobre o contexto social mais amplo.

\section{Metodologia}

Para responder às nossas questões de pesquisa, coletamos três posts da página do Facebook do jornal O Globo, que é a página de jornal impresso em atividade com o maior número de curtidas na plataforma (5.743.166 seguidores ${ }^{2}$ ) - a página do jornal Folha de S.Paulo ainda possui um maior engajamento, porém, o

2 Dados do dia 3 de setembro de 2020. 
cadernos pagu (59), 2020e205913 Por que o termo feminicídio incomoda tanto?

jornal deixou de utilizá- la por decisão editorial tomada em fevereiro de 2018. Escolhemos três posts publicados por O Globo que abordam o feminicídio de maneira distinta e que foram veiculados entre abril e dezembro de 2017. O primeiro post busca levantar uma discussão geral sobre o feminicídio. A chamada é a seguinte: "O termo feminicídio foi a coisa mais idiota que já inventaram'. Concorda?". O segundo post não faz qualquer referência direta ao feminicídio, e apenas divulga a notícia de um homem que assassinou a namorada a facadas. No terceiro post, o próprio jornal, ao noticiar um assassinato de uma mulher, caracteriza-o como feminicídio. A escolha por posts de abordagens diferentes possibilita uma análise comparativa de discussões desencadeadas por diferentes mecanismos. Os três posts possuem, respectivamente, 407, 235 e 586 comentários, totalizando 1.227. Classificamos os comentários entre relevantes e não relevantes aqueles que fugiam completamente do tema, e/ou possuem avaliação simples (ex. "muito bom") ou sem sentido.

Os 1.046 comentários classificados como relevantes foram analisados por meio da metodologia Análise de Conteúdo (Krippendorf, 2003), a partir da identificação das seguintes categorias analíticas:

I) Gênero do usuário: a) mulher; b) homem; c) não identificado;

II) Enquadramento do crime: a) feminicídio/ênfase no fato de a vítima ser mulher; b) homicídio comum; c) não se aplica;

III)Atribuição de culpa: a) apenas culpabiliza a mulher/vítima; b) condena o crime, mas culpabilizam a mulher; c) culpabiliza o agressor em tom de crime comum; d) culpabiliza o agressor, enquanto homem, relacionando ao fato de a vítima ser mulher (feminicídio); e) culpabiliza o estado/legislação brasileira; f) cultura/sociedade de maneira geral; g) outros h) não se aplica;

IV) Respeito/Desrespeito: a) uso de linguagem chula; b) linguagem neutra/respeitosa;

V) Acordo/Desacordo: a) Presença de acordo; b) Presença de desacordo c) não se aplica; 
VI) Foco da interação (Acordo/Desacordo): a) conteúdo do post, b) usuária mulher; c) usuário homem; d) outro com posicionamento contrário; e) outro; f) comentário não endereçado;

VII) Argumentos contrários e favoráveis à Lei do Feminicídio:

\begin{tabular}{|c|c|}
\hline CONTRÁRIOS & FAVORÁVEIS \\
\hline $\begin{array}{l}\text { As mulheres não morrem mais do que os homens, } \\
\text { pelo contrário, ser mulher é mais seguro. }\end{array}$ & $\begin{array}{l}\text { Ainda falta entendimento sobre a violência } \\
\text { contra a mulher e a lei do feminicídio ajuda a } \\
\text { chamar atenção para isso. }\end{array}$ \\
\hline Todos somos iguais perante a lei. & $\begin{array}{l}\text { A Lei do Feminicídio contribui para melhorar a } \\
\text { forma como a justiça analisa os casos de } \\
\text { violência contra a mulher. }\end{array}$ \\
\hline $\begin{array}{l}\text { Fazer a distinção só atrapalha, a tendência vai ser } \\
\text { separar tudo, ex. "gaycídio", "idocídio", } \\
\text { "transídio", o que não leva a lugar nenhum. }\end{array}$ & $\begin{array}{c}\text { A Lei do Feminicídio é um importante } \\
\text { complemento à Lei Maria da Penha no combate } \\
\text { à violência contra a mulher. }\end{array}$ \\
\hline $\begin{array}{c}\text { Mulheres também matam seus companheiros e } \\
\text { suas companheiras. }\end{array}$ & $\begin{array}{c}\text { Mulheres morrem somente pelo fato de ser } \\
\text { mulher. }\end{array}$ \\
\hline $\begin{array}{c}\text { Já existe o homicídio/a legislação já dá conta } \\
\text { desses crimes, por isso, o feminicídio não é } \\
\text { necessário. }\end{array}$ & $\begin{array}{c}\text { O índice de assassinato de mulheres pelo } \\
\text { simples fato de ser mulher é muito alto e/ou está } \\
\text { aumentando. }\end{array}$ \\
\hline $\begin{array}{c}\text { Uma mulher não morre por ser mulher, existem } \\
\text { outros motivos, que não justificam o termo } \\
\text { feminicídio. }\end{array}$ & $\begin{array}{c}\text { É uma forma de tematizar e, portanto, combater } \\
\text { o machismo e a desigualdade entre homens e } \\
\text { mulheres. }\end{array}$ \\
\hline $\begin{array}{c}\text { O problema é a impunidade, não a falta de novas } \\
\text { leis. }\end{array}$ & $\begin{array}{l}\text { Homens são os principais agressores e } \\
\text { responsáveis pela violência contra a mulher. }\end{array}$ \\
\hline $\begin{array}{c}\text { A vida da mulher não vale mais do que a do } \\
\text { homem. }\end{array}$ & $\begin{array}{l}\text { Frequentemente, mulheres são mortas pelos } \\
\text { companheiros no ambiente doméstico. }\end{array}$ \\
\hline Outros & Outros \\
\hline
\end{tabular}

Duas codificadoras codificaram $10 \%$ do material para realizar o teste de confiabilidade. Ao todo, foram codificados 39 comentários do post da matéria sobre o feminicídio de maneira geral, 52 comentários sobre a notícia de um crime nomeado como feminicídio e 20 comentários sobre a notícia do assassinato de uma mulher. Nenhuma variável ficou aquém do nível mínimo de 
cadernos pagu (59), 2020e205913 Por que o termo feminicídio incomoda tanto?

confiabilidade recomendado de $\alpha=0,66$ (Krippendorf, 2003). Os resultados completos estão apresentados na tabela abaixo:

Tabela 1: Teste de confiabilidade

\begin{tabular}{llc}
\hline Variáveis & $\alpha$ & Porcentagem de acordo \\
\hline Gênero do usuário & 0.96 & $98.2 \%$ \\
Enquadramento & 0.817 & $90.8 \%$ \\
Atribuição de culpa & 0.713 & $95.4 \%$ \\
Respeito/Desrespeito & 0.725 & $86.2 \%$ \\
Acordo/Desacordo & 0.777 & $91.7 \%$ \\
Foco da interação & 0.669 & $90.8 \%$ \\
Argumentos & 0.667 & $99.1 \%$ \\
\hline
\end{tabular}

Resultados

Nosso primeiro questionamento está relacionado à forma como os cidadãos enquadram os casos de violência contra mulher, com o objetivo de analisar em que medida os comentários fazem algum tipo de correlação entre os crimes e o fato de a vítima ser mulher. Se observamos de maneira agregada, todos os comentários que apresentaram algum tipo de enquadramento, $73 \%$ enquadraram o crime como homicídio e apenas $27 \%$ como feminicídio. Ao observarmos os dados separadamente, de acordo com o tipo de notícia, os comentários daquela notícia que aborda o assassinato sem nomeá-lo como feminicídio (C) enquadraram o crime, principalmente, como homicídio, enquanto nas outras duas notícias ( $\mathrm{A}$ e B), a maior parte dos comentários não apresentou nenhum tipo de enquadramento (ver Tabela 2). No caso da matéria geral sobre feminicídio (B), já era esperado o fato de os comentários não apresentarem um enquadramento sobre um crime, uma vez que ela não noticiava um ato de violência letal 
contra a mulher, propondo apenas um debate sobre o tema e o uso do termo. Contudo, quando comparamos as duas matérias que relatam um assassinato, os comentários naquela que aborda o crime como feminicídio (A) se aproxima mais da matéria geral (B) do que daquela que também noticia um assassinato $(\mathrm{C})$, ou seja, mais da metade dos comentários não busca enquadrar o crime. Isso sugere que, no caso da matéria que relata um assassinato enquanto um feminicídio (A), as pessoas focaram mais a discussão no termo utilizado (feminicídio) e não no crime em si.

Tabela 2: Enquadramento do crime nos comentários x Tipo de notícia

\begin{tabular}{lccc}
\hline Enquadramento & $\begin{array}{c}\text { Matéria geral sobre } \\
\text { o uso do termo } \\
\text { feminicídio }\end{array}$ & $\begin{array}{c}\text { Notícia que } \\
\text { nomeia um crime } \\
\text { como feminicídio }\end{array}$ & $\begin{array}{c}\text { Notícia sobre o } \\
\text { assassinato de } \\
\text { uma mulher }\end{array}$ \\
\hline Feminicídio & $11 \%$ & $10 \%$ & $11 \%$ \\
Homicídio & $14 \%$ & $28 \%$ & $\mathbf{5 0 \%}$ \\
Não se aplica & $\mathbf{7 6 \%}$ & $\mathbf{6 2 \%}$ & $39 \%$ \\
Total & $100 \%$ & $100 \%$ & $100 \%$ \\
\hline
\end{tabular}

Fonte: Dados da pesquisa.

Além do enquadramento, também buscamos identificar de que forma os cidadãos atribuem culpa para a violência sofrida por mulheres, que, de certa forma, também se relaciona ao enquadramento que é dado aos crimes. Assim como no caso do enquadramento, nos comentários na matéria que discute o uso do termo feminicídio de maneira geral (B), como já esperado, em sua maioria, não há atribuição de culpa (93\%). Na notícia que aborda o assassinato de uma mulher como feminicídio (A), a maioria dos comentários também não apresenta atribuição de culpa (67\%). Os comentários da notícia de um assassinato não classificado como feminicídio (C) atribuem culpa, principalmente, ao assassino, porém, em tom de crime comum (41\%). A tabela abaixo mostra os dados completos: 
cadernos pagu (59), 2020e205913 Por que o termo feminicídio incomoda tanto?

Tabela 3: Atribuição de culpa nos comentários x Tipo de notícia

\begin{tabular}{lccc}
\hline \multicolumn{1}{c}{$\begin{array}{c}\text { Atribuição de } \\
\text { culpa }\end{array}$} & $\begin{array}{c}\text { Feminicídio } \\
\text { Geral }\end{array}$ & $\begin{array}{c}\text { Assassinato } \\
\text { como } \\
\text { feminicídio }\end{array}$ & $\begin{array}{c}\text { Assassinato } \\
\text { comum }\end{array}$ \\
\hline Mulher & $2 \%$ & $4 \%$ & $2 \%$ \\
$\begin{array}{l}\text { Condena o crime, } \\
\text { mas culpabiliza a } \\
\text { mulher }\end{array}$ & $0 \%$ & $7 \%$ & $6 \%$ \\
$\begin{array}{l}\text { Agressor, em tom } \\
\text { de crime comum }\end{array}$ & $0 \%$ & $16 \%$ & $\mathbf{4 1 \%}$ \\
$\begin{array}{l}\text { Agressor enquanto } \\
\text { homem/machismo }\end{array}$ & $1 \%$ & $5 \%$ & $12 \%$ \\
$\begin{array}{l}\text { Estado/legislação } \\
\text { branda/impunidade }\end{array}$ & $3 \%$ & $1 \%$ & $5 \%$ \\
$\begin{array}{l}\text { Sociedade/cultura } \\
\text { machista }\end{array}$ & $1 \%$ & $0 \%$ & $0 \%$ \\
Outro & $0 \%$ & $0 \%$ & $1 \%$ \\
Não se aplica & $\mathbf{9 3 \%}$ & $\mathbf{6 7 \%}$ & $32 \%$ \\
Total & $100 \%$ & $100 \%$ & $100 \%$ \\
\hline
\end{tabular}

Fonte: Dados da pesquisa.

Em relação à presença de acordo e desacordo, a discordância é maior nas matérias que nomeiam o feminicídio (A e B) do que naquela que noticia o caso de assassinato sem utilizar o termo (C) (ver Tabela 4). Se olharmos o foco da interação, a maior parte dos comentários nos três posts não está endereçado a alguém, mas, quando está, é, sobretudo, a homens e mulheres (ver Tabela 5), o que pode indicar que a maior discordância ocorre entre eles. 
Tabela 4: Tipo de notícia x Presença de acordo e desacordo

\begin{tabular}{lccc}
\hline Acordo/Desacordo & Feminicídio Geral & $\begin{array}{c}\text { Assassinato como } \\
\text { feminicídio }\end{array}$ & $\begin{array}{c}\text { Assassinato } \\
\text { comum }\end{array}$ \\
\hline Acordo & $3 \%$ & $5 \%$ & $1 \%$ \\
Desacordo & $66 \%$ & $59 \%$ & $25 \%$ \\
Não se aplica & $31 \%$ & $36 \%$ & $74 \%$ \\
Total & $100 \%$ & $100 \%$ & $100 \%$ \\
\hline
\end{tabular}

Fonte: Dados da pesquisa.

Tabela 5: Foco da interação $x$ Tipo de notícia

\begin{tabular}{lccc}
\hline \multicolumn{1}{c}{$\begin{array}{c}\text { Foco da } \\
\text { interação }\end{array}$} & $\begin{array}{c}\text { Feminicídio } \\
\text { Geral }\end{array}$ & $\begin{array}{c}\text { Assassinato como } \\
\text { feminicídio }\end{array}$ & $\begin{array}{c}\text { Assassinato } \\
\text { comum }\end{array}$ \\
\hline $\begin{array}{l}\text { Conteúdo } \\
\text { post/notícia }\end{array}$ & $10 \%$ & $11 \%$ & $3 \%$ \\
Usuária mulher & $\mathbf{2 3 \%}$ & $\mathbf{2 2 \%}$ & $\mathbf{1 0 \%}$ \\
$\begin{array}{l}\text { Usuário homem } \\
\text { Outro (s) com }\end{array}$ & $\mathbf{2 6 \%}$ & $\mathbf{2 1 \%}$ & $\mathbf{1 2 \%}$ \\
$\begin{array}{l}\text { posicionamento } \\
\text { contrário }\end{array}$ & $2 \%$ & $6 \%$ & $0 \%$ \\
$\begin{array}{l}\text { Outro } \\
\text { Não endereçado }\end{array}$ & $31 \%$ & $4 \%$ & $0 \%$ \\
Total & $100 \%$ & $36 \%$ & $74 \%$ \\
\hline
\end{tabular}

Fonte: Dados da pesquisa

Quando cruzamos a presença de desacordo com o gênero da pessoa que comenta, de maneira agregada em todos os três posts, os dados reforçam que mulheres discordam mais de homens $e$ vice-versa (ver tabela 6). Isso pode indicar que os posicionamentos e preferências em relação ao reconhecimento da 
cadernos pagu (59), 2020e205913 Por que o termo feminicídio incomoda tanto?

existência de feminicídio está relacionado também ao gênero de quem comenta: homens tendem a questionar a necessidade do uso do termo, enquanto mulheres defendem a importânciade de dar visibilidade ao fato de que há mulheres que morrem apenas pelo fato de serem mulheres. Os argumentos mobilizados para defender ou criticar a Lei do Feminicídio e, consequentemente, a tipificação do crime enquanto um qualificador do homicídio, e o gênero de quem argumenta também dizem muito sobre como homens e mulheres entendem a violência de gênero. A maior parte dos comentários não convocou nenhum tipo de argumento (78\%). Apesar de terem sido poucos os comentários com justificação, é interessante observar o gênero de quem apresentou justificativa. Os argumentos contrários à tipificação foram convocados, em sua maioria, por homens (89\%), sendo os dois mais presentes: "Já existe o homicídio/a legislação já dá conta desses crimes, por isso, o feminicídio não é necessário" (22\%); e "Mulheres também matam seus companheiros $e$ suas companheiras" (16\%). Já os favoráveis à Lei e ao uso do termo feminicídio foram mais convocados por mulheres (81\%), sendo os principais: "Mulheres morrem somente pelo fato de ser mulher" (42\%); e "Homens são os principais agressores e responsáveis pela violência contra a mulher" (23\%).

Tabela 6: Direcionamento da discordância x Gênero do usuário

\begin{tabular}{lccccc}
\hline & $\begin{array}{c}\text { Discordância } \\
\text { de homens }\end{array}$ & $\begin{array}{c}\text { Discordância } \\
\text { de mulheres }\end{array}$ & $\begin{array}{c}\text { Discordância } \\
\text { do conteúdo } \\
\text { do post }\end{array}$ & Outros & Total \\
\hline Homem & $23 \%$ & $\mathbf{3 8 \%}$ & $23 \%$ & $17 \%$ & $100 \%$ \\
Mulher & $\mathbf{5 0 \%}$ & $31 \%$ & $8 \%$ & $11 \%$ & $100 \%$ \\
\hline
\end{tabular}

Fonte: Dados da pesquisa

Por fim, investigamos a forma como as pessoas comentaram nos posts, observando se utilizaram linguagem neutra/respeitosa ou linguagem chula. A maior parte dos comentários nos posts de todas as três notícias utilizou linguagem neutra/respeitosa (70\%), porém, o uso de linguagem desrespeitosa está mais fortemente 
associado aos comentários que apresentaram desacordo com a tipificação do feminicídio (77\%). Além disso, quando há desacordo, o percentual de linguagem desrespeitosa é alto (53\%), se comparado aos comentários em que há acordo $(21 \%)$ e aqueles que não demonstram nem acordo nem desacordo (16\%), conforme tabela abaixo:

Tabela 7: Acordo e desacordo x Respeito/Desrespeito

\begin{tabular}{lccc}
\hline & Acordo & Desacordo & Não se aplica \\
\hline $\begin{array}{l}\text { Linguagem } \\
\text { Neutra/Respeitosa }\end{array}$ & $79 \%$ & $\mathbf{5 3 \%}$ & $84 \%$ \\
$\begin{array}{l}\text { Linguagem } \\
\text { Desrespeitosa }\end{array}$ & $21 \%$ & $\mathbf{4 7 \%}$ & $16 \%$ \\
Total & $100 \%$ & $100 \%$ & $100 \%$ \\
\hline
\end{tabular}

Fonte: Dados da pesquisa

Discussão dos resultados

Os dados comparativos entre os comentários nos posts das três notícias revelaram um aspecto curioso: os comentários da matéria que noticia um assassinato e o nomeia como feminicídio (A) se aproximam mais da matéria que discute o uso do termo feminicídio de maneira geral (B) do que da matéria que noticia um crime sem nomeá-lo como feminicídio (C). Essa semelhança se deu tanto em relação ao enquadramento quanto à atribuição de culpa e à expressão de desacordo. Em relação ao enquadramento, os cidadãos que comentaram no post da matéria geral sobre feminicídio (B) e naquela que noticia um caso de feminicídio, assim o nomeando (A), estavam mais preocupados em discutir a legitimidade do uso do termo para caracterizar a violência letal contra a mulher, enquanto que na matéria que noticia um caso de violência sem nomeá-lo como feminicídio $(\mathrm{C})$, há ocorrência maior 
cadernos pagu (59), 2020e205913 Por que o termo feminicídio incomoda tanto?

de comentários que discutiam e condenavam o crime. Os comentários $^{3}$ abaixo são exemplos disso:

\begin{tabular}{ll}
\hline Tipo de matéria & Comentário no post \\
\hline $\begin{array}{l}\text { Matéria que noticia a violência letal contra } \\
\text { uma mulher como feminicídio (A) }\end{array}$ & $\begin{array}{l}\text { "Sobre quando o assassinado é o homem, } \\
\text { você ja viu algum homem ser assassinado } \\
\text { pelo gênero? Pelo simples fato de ser } \\
\text { homem? Esses termos vieram para ajudar } \\
\text { a o que vemos no cotidiano."4 }\end{array}$ \\
$\begin{array}{lll}\text { Matéria geral sobre feminicídio (B) } & \text { "Para os que defendem o conceito de } \\
& \text { 'feminicídio' por razões ideológicas, a } \\
\text { resposta é: Arrume um trabalho." }\end{array}$ \\
$\begin{array}{l}\text { Matéria que noticia a violência letal contra } \\
\text { uma mulher sem nomeá-lo como }\end{array}$ & $\begin{array}{l}\text { "Homem Sem Caráter, ninguém tem esse } \\
\text { direito, de parar a vida de ninguém, o pai } \\
\text { feminicídio (C) }\end{array}$ \\
$\begin{array}{l}\text { cria uma filha com todo amor e carinho, } \\
\text { pra vim um lixo humano e tirar a vida de } \\
\text { uma filha, esse lixo tem ser fuzilado sem } \\
\text { piedade". }\end{array}$ \\
\hline
\end{tabular}

O tipo de enquadramento também revela a tendência de os casos envolvendo violência letal contra a mulher serem tratados como casos isolados, sem levar em consideração um contexto maior de recorrência, que os próprios dados estatísticos nacionais sobre o problema revelam. É comum os agressores serem classificados como psicopatas e perturbados e não como consequência e frutos de uma estrutura social marcada pela desigualdade de gênero. Por isso também, esses crimes, frequentemente, são classificados como passionais, como um problema envolvendo um casal específico e não como um problema social, o que faz com que sejam entendidos como

\footnotetext{
${ }^{3}$ Todos os comentários foram transcritos na íntegra, omitindo o nome do usuário que comentou.

${ }^{4}$ Este comentário é uma resposta a outro que questionava o uso do termo feminicídio, argumentando que homens morrem mais.

${ }^{5}$ Este comentário foi codificado como enquadrando o crime como homicídio comum, uma vez que a pessoa não faz nenhum tipo de referência explícita ao feminicídio e nem ao fato de o agressor ser um homem e a vítima uma mulher. É um comentário que aborda o crime como algo isolado.
} 
menos graves, inclusive pelas instâncias judiciais (Pasinato, 2011). $\mathrm{O}$ fato de esses crimes serem tratados como casos isolados $e$ passionais os liga a argumentos que questionam "até que ponto deve-se interferir na esfera privada". A própria justiça tende a não interferir na esfera doméstica, partindo da avaliação de que, nela, o que predomina é o afeto (Biroli, 2014). Essa ideia acaba por favorecer a ocorrência de crimes domésticos, uma vez que "o mundo dos afetos é também aquele em que muitos abusos puderam ser perpetuados em nome da privacidade e da autonomia da entidade familiar em relação às normas aplicáveis ao espaço público" (Biroli, 2014: 34). Dessa forma, tratar os crimes como passionais e como algo relativo à esfera privada também favorece a ideia de que a mulher teria certa responsabilidade, que poderia, de alguma forma, impedir esse tipo crime, por exemplo, tomando mais cuidado ao escolher seus companheiros, como alguns comentários nos posts sugerem.

Ao analisarmos os dados relativos à atribuição de culpa, ocorre algo parecido com o enquadramento: os comentários na matéria sobre o assassinato comum (C) apresentam mais atribuições de culpa do que os comentários na matéria sobre o crime definido como feminicídio (A). Isso também sugere que quando o termo feminicídio é utilizado, existe a tendência de as pessoas discutirem mais a utilização do termo do que o próprio crime que é noticiado e as possíveis soluções para enfrentá-lo, conforme exemplos abaixo:

\footnotetext{
Tipo de matéria

Comentário no post

"Porra, tudo agora é de homem e de mulher, vão

Matéria que noticia a violência letal para pqp, q mundo chato do caralho, homicídio, contra uma mulher como feminicídio ou vão mudar também a nossa expecie de homo (A) sapiens para homens e mulheres sapiens para mulheres, vão a merda"

Matéria geral sobre feminicídio (B)

"Não estou tentando defender agressores de mulheres, muito menos minimizar seus atos, mas sinceramente não vejo real utilidade em definir como um novo crime o assassinato de mulheres, ou de homossexuais, transexuais, ou de crianças, idosos, negros, índios, cristãos, espíritas, etc.
} 
Todos são homicídios, devendo ser considerados agravantes se existe motivo torpe, se a vítima não tinha condição de se defender, etc. Devemos debater o tema, educar as pessoas, pois não vai fazer diferença criar inúmeros termos para especificar cada tipo de homicídio...

Matéria que noticia a violência letal contra uma mulher sem nomeá-lo

"Caraí não é homem não esse é o capeta".

como feminicídio $(\mathrm{C})$

As diferenças e semelhanças entre os comentários nos posts das matérias sugerem que o uso do termo "feminicídio" pode incomodar mais do que a própria ocorrência da violência contra uma mulher. Esse incômodo também se reflete na presença de desacordo, que é maior exatamente na matéria que utiliza o termo feminicídio (A) e naquela que propõe uma discussão sobre ele (B). As pessoas, de certa forma, se "esquecem" que o foco da notícia é um assassinato de uma mulher e passam a centrar a discussão na legitimidade do uso do termo. O diálogo abaixo, retirado dos comentários do post que enquadrava o crime como feminicídio (A), é um exemplo disso:

Usuário homem 1:

- "Feminicidio é a forma deles dizerem que a vida dá mulher vale mais que a do homem, logo a punição é mais severa. Que democracia linda né?"

Usuária mulher 1:

- "Não, [fulano], feminicídio é uma forma de aumentar a pena do sujeito que mata uma mulher pelo simples fato dela ser mulher. Violência contra o gênero feminino. Lê a lei que aí vc não precisa escrever merda aqui".

$-$

Usuário homem 2:

- "Feminicídio é a bunda de quem escreveu a matéria! É a bunda do editor chefe! É a bunda do jornalista! Isso se chama HOMICÍDIO, PORRA!!!"

Usuária mulher 2: 
- "Só homem revoltado com a alteração do nome. Por causa de pessoas COMO VCS é que o FEMINICÍDIO OCORRE".

Usuária mulher 3:

- "Uma mulher grávida foi assassinada, mas oq causa revolta é a palavra "feminicidio"?? É isso msm?? Pqp! Parem de passar vergonha homens!"

O desvio de foco do crime noticiado para o uso do termo feminicídio pode não ser algo negativo, uma vez que uma discussão é aberta e diferentes pontos de vista são defendidos e isso pode trazer ganhos epistêmicos (Chambers, 2017; Maia et al., 2018). Nesse sentido, a presença de desacordo também pode ser positiva para uma discussão, uma vez que ao discordar, as pessoas podem apresentar argumentos que justifiquem seus pontos de vista. Contudo, se observarmos a argumentação nos comentários, os resultados mostram que as pessoas, em sua maioria, não apresentaram nenhum tipo de argumento para justificar o porquê de serem a favor ou contra à Lei e ao uso do termo feminicídio, o que mostra que a discussão ficou apenas no nível da discordância. Além disso, apesar de o número de comentários que utilizam uma linguagem neutra e respeitosa ser maior, quando observamos a ocorrência de linguagem desrespeitosa, ela é mais alta em comentários que apresentam desacordo, se comparados aos comentários em que há acordo e aqueles que não demonstram nem acordo nem desacordo. $\mathrm{O}$ desrespeito também nem sempre é algo ruim para a deliberação (Sarmento e Mendonça, 2016), contudo, no caso aqui estudado, ele aparece como uma forma de agredir o outro com o qual se discorda e, em alguns casos, é reflexo de intolerância, como no exemplo: "Já basta a gorda do cabelo azul do "Grobo" ainda vem as feminazi surtar porque tem gente que acha imbecil essa merda de "feminicídio". Vapaputaqueopariu"6.

${ }^{6}$ Comentário retirado do post da notícia que nomeia o assassinato de uma mulher como feminicídio. 
cadernos pagu (59), 2020e205913 Por que o termo feminicídio incomoda tanto?

Outro ponto é o fato de as discordâncias estarem relacionadas ao gênero oposto, ou seja, mulheres discordaram mais de homens e vice-versa. Existe um acirramento de posições entre os dois gêneros: enquanto mulheres argumentam que os homens são os principais agressores, os homens argumentam que mulheres também matam. No geral, as mulheres tendem a defender a tipificação do feminicídio para a violência letal de gênero, enquanto os homens questionam a real necessidade dessa diferenciação, o que sugere que eles buscam questionar a existência de violência de gênero, negando, inclusive que sejam os principais agressores. Comentários que argumentam que homens morrem mais, que mulheres também matam e que a vida delas não vale mais do que a dos outros são exemplos disso:

\begin{tabular}{ll}
\hline Tipo de matéria & Comentário no post \\
\hline Matéria que noticia a violência letal contra & "Feminicídio??? É diferente matar uma \\
umulher e matar um homem então!? E roubar & uma mulher é mais grave que roubar um \\
homem também? E num assalto a uma \\
mulher o assaltante matar o marido? É menos \\
grave?" \\
"Porque para cada mulher assassinada no \\
Brasil, morrem 11 homens. Inclusive os \\
homens mortos nas relações familiares (morto \\
pela companheira ou companheiro, por um \\
dos pais ou irmãos, etc) ultrapassa o \\
número de mulheres mortas na mesma \\
situação".
\end{tabular}

Esses argumentos que buscam negar o que os próprios dados estatísticos mostram, ou seja, que cada vez mais mulheres morrem pelo fato de serem mulheres, não deixa de ser também um reflexo da própria sociedade. $\mathrm{O}$ não reconhecimento das especificidades desse crime é também uma forma de perpetuá-lo.

Em alguns argumentos contrários à judicialização da violência de gênero em geral, encontram-se argumentos claramente patriarcais, na medida em que impedem a identificação da dor, do sofrimento, da brutalidade da 
morte implicada nos feminicídios e o significado disto no contexto de relações sociais extremamente desiguais (Gomes, 2018:11-12).

Sarmento (2014), ao analisar o debate mediado sobre a Lei Maria da Penha, encontrou certa "dificuldade na compreensão da violência doméstica enquanto um fenômeno que comprometeu a plena vivência de direitos das mulheres, historicamente atingidas pelos crimes regulados pela Lei Maria da Penha" (p. 106). Essa mesma desvinculação da violência à desigualdade de gênero também é encontrada nos comentários aqui analisados, que ou negam e questionam a existência de feminicídio ou condenam a violência, mas como algo isolado. Tudo isso só reforça a importância de a violência letal contra as mulheres ser contextualizada e nomeada, também pelos media, para identificar suas circunstâncias, para o imaginário social e, consequentemente, para enfrentá-la (Gomes, 2018; Luengo, 2017; Marcuello-Servós et al, 2016; Pasinato, 2011; Segato, 2006; Weil, 2016).

\section{Considerações finais}

Este artigo teve como objetivo analisar como cidadãos ordinários entendem e discutem a violência letal contra a mulher por meio de comentários na página do jornal $\mathrm{O}$ Globo no Facebook, e como os diferentes posicionamentos se relacionam ao enquadramento do post que originou os comentários. Todos os dados apresentados revelam certa resistência ao uso do termo feminicídio $e$, consequentemente, ao reconhecimento de que existe violência de gênero, sendo os homens os principais agressores de mulheres. Os casos de feminicídio não são nomeados como tal e tendem a ser tratados como casos isolados $e$ crimes passionais. A resistência à tipificação do feminicídio está principalmente entre os homens, que, em sua maioria, não veem justificativa para fazer essa distinção entre violência letal contra mulheres e contra homens. Também foi identificado que homens e mulheres discordam mais entre si e, quando o fazem, tendem a 
cadernos pagu (59), 2020e205913 Por que o termo feminicídio incomoda tanto?

usar uma linguagem desrespeitosa e ofensiva. De um lado, estão as mulheres defendendo a importância de se tipificar o feminicídio, de outro, os homens negando que são os principais agressores.

Além disso, apesar haver uma ocorrência mais baixa do que a atribuição de culpa ao agressor, chama atenção o fato de haver comentários que culpabilizam a mulher, seja condenando o crime ou colocando a culpa unicamente na vítima. Comentários como "Muitas Mulheres não sabem diferenciar homem de marginal, então está aí o resultado" e "As mulheres é que não estão sabendo escolher. Ficam procurando homens que possam proporcionar emoções forte em vez de aprenderem a proporcionar a si mesma enquanto sozinhas" são exemplos disso. Negar ou questionar o fato de mulheres serem mortas simplesmente por serem mulheres é também ignorar o que mostram os dados estatísticos: o aumento das notificações dos casos de violência letal contra mulheres. Comentários contrários à Lei do Feminicídio, que negam a existência da violência de gênero, argumentando que homens morrem mais e que mulheres também matam, por exemplo, ignoram que os homens são os principais responsáveis pela morte de mulheres e que esses não são casos isolados.

Este artigo possui limitações em relação à quantidade de notícias analisadas e também por não explorar a interseccionalidade, uma vez que os dados também mostram que as mulheres negras são as principais vítimas de violência, além de a raça $e$ a classe das vítimas e dos agressores poder interferir no teor dos comentários. Uma análise com um banco de dados maior e que observe questões de raça e classe pode render discussões de maior relevância. Contudo, nossos resultados já reforçam o desafio que é pautar e nomear a violência de gênero, e como esse gesto também é uma forma de enfrentá-la. Além de o uso do termo feminicídio incomodar mais a uma parcela expressiva da sociedade do que a ocorrência dos crimes em si, a mulher ainda é vista como uma potencial culpada das situações de violências que sofre. 
Os questionamentos e resistências em relação à Lei do Feminicídio estão diretamente relacionados às opressões de gênero, que são estruturais na sociedade brasileira, mas também podem ser associados à falta de diálogo sobre a temática. Não houve um investimento em campanhas de informação $e$ sensibilização sobre o tema, o que implica que grande parte da população tenda a pensar que "o homicídio de um homem é tão grave quanto de uma mulher" e que se mantenha o argumento de que "os homens morrem mais", conforme revelam os dados da pesquisa. Isso mostra a importância da implementação de políticas públicas sempre associadas ao diálogo $e$ ao debate, para que novas legislações tenham receptividade entre a população.

\section{Referências bibliográficas}

ANDRADE, Luciana; MATOS, Marlise. A criminalização da violência contra as mulheres no brasil: de "legítima defesa da honra" à violação dos direitos humanos. Revista Sociais e Humanas (30), Santa Maria RS, 2017 [http://dx.doi.org/10.5902/2317175827565 - acesso em 17 de janeiro de 2019].

ANGÉLICO, Rocio; DIKENSTEIN, Violeta; FISCHBERG, Sabrina; MAFFEO,Florencia. El feminicidio y laviolencia de género enla prensa argentina: unanálisis de voces, relatos y actores. Universitas Humanística (78), Bogotá - Colombia, 2014, pp.281-303 [http://www.scielo.org.co/scielo.phppid=S012048072014000200013 \&script $=$ sci_abstract\&tlng $=$ es - acesso em 08 de outubro de 2020].

BANDEIRA, M. L.; VIEIRA, L.; CAMPOS,S.F. Enquadramento midiático dos crimes de feminicídio no Brasil: $\mathrm{O}$ padrão de reprodução e a invisibilidade de mulheres assassinadas. Artigo a ser apresentado no XXX1 Congresso Alas, Montevideu - Uruguai, 2017 - mimeo.

BARROS, Samuel; CARREIRO, Rodrigo. O Facebook como plataforma para o comentário de notícias: uma análise da deliberatividade em cinco temas. In: MENDONÇA, R.; SAMPAIO, R.; BARROS, S (org.). Deliberação Online no Brasil: entre iniciativas de democracia digital e redes sociais de conversação. Salvador - BA, EDUFBA, 2017 [http://repositorio.ufba.br/ri/handle/ri/19267 _ acesso em 08 de outubro de 2020]. 
cadernos pagu (59), 2020e205913 Por que o termo feminicídio incomoda tanto?

BIROLI, Flávia. Mulheres e política nas notícias: Estereótipos de gênero e competência política. Revista Crítica de Ciências Sociais (90), Coimbra - Portugal, 2010, pp.45-69. [https://journals.openedition.org/rccs/1765 - acesso em 17 de janeiro de 2019].

BIROLI, Flávia. O público e o privado. In: MIGUEL, Luis Felipe; BIROLI, Flávia. Feminismo e política. São Paulo - SP, Boitempo, 2014, pp.3146.

BLACK, Laura W. Listening to the City: Difference, Identity, and Storytelling in Online Deliberative Groups, Journal of Public Deliberation

(5), 2009 [https://www.publicdeliberation.net/jpd/vol5/iss1/art4 - acesso em 17 de janeiro de 2019].

BLAY. Eva A. Violência contra a mulher e políticas públicas. Estudos Avançados (17), São Paulo - SP, 2003, pp.87-98 [http://dx.doi.org/10.1590/S0103-40142003000300006 - acesso em 17 de janeiro de 2019].

BOHMAN, James. Expanding dialogue: The Internet, the public sphere and prospects for transnational democracy. Sociological Review (52), 2004 , pp.131-155 [https://doi.org/10.1111/j.1467954X.2004.00477.X - acesso em 17 de janeiro de 2019].

CHAMBERS, Simone. Balancing epistemic quality and equal participation in a system approach to deliberative democracy. Social Epistemology (31), United Kingdom, 2017, pp.266-276 [https://doi.org/10.1080/02691728.2017.1317867 - acesso em 17 de janeiro de 2019].

COHEN, Joshua. Deliberação e legitimidade democrática. In: MARQUES, Angela (org.). A deliberação pública e suas dimensóes sociais, políticas e comunicativas. Belo Horizonte - MG, Autêntica, 2009, pp.85-108.

DAHLGREN, Peter. The Internet, Public Spheres, and Political Communication: Dispersion and Deliberation. Political Communication (22), United Kingdom, 2005, pp.147-162 [https://doi.org/10.1080/10584600590933160 - acesso em $17 \mathrm{de}$ janeiro de 2019]. 
FRASER, Nancy. Rethinking the Public Sphere: A Contribution to the Critique of Actually Existing Democracy. Social Text (25/26), Durham - US, 1990, pp. 56-80 [https://www.jstor.org/stable/466240?seq=1\#page scan tab contents - acesso em 17 de janeiro de 2019].

GERVAIS, Bryan. Incivility Online: Affective and Behavioral Reactions to Uncivil Political Posts in a Web-based Experiment. Journal of Information Technology \& Politics, United Kingdom, 2015, pp.167185 [https://doi.org/10.1080/19331681.2014.997416 - acesso em 17 de janeiro de 2019].

GOMES, Izabel Solyszko. Feminicídios: um longo debate. Revista de Estudos Feministas (26), Florianópolis - SC, 2018 [http://dx.doi.org/10.1590/1806-9584-2018v26n239651 - acesso em 17 de janeiro de 2019].

GOODIN, Robert E. Sequencing Deliberative Moments. Acta Politica (40), Basingstoke - U.K., 2005, pp.182-196.

HABERMAS, Jürgen. Direito e Democracia entre facticidade e validade vol.2. Rio de Janeiro - RJ, Tempo Brasileiro, 2011.

KRIPPENDORFF, Klaus. Content Analysis: an introduction to its methodology. California - US, Sage Publication, 2003.

LUENGO, María. Gender violence: the media, civil society, and the struggle for human rights in Argentina. Media, Culture \& Society (40), California - US, 2017, pp.397-414 [https://doi.org/10.1177/0163443717713259 - acesso em 17 de janeiro de 2019].

MACHADO, Isadora Vier; ELIAS, Maria Lígia G. G. Rodrigues. Feminicídio em cena: Da dimensão simbólica à política. Tempo Social (30), São Paulo - SP, 2018 [http://dx.doi.org/10.11606/01032070.ts.2018.115626 - acesso em 17 de janeiro de 2019].

MAGALHÃES-DIAS, Carolina; LOBO, Soraia. Changing representations of intimate partner femicides by a portuguese newspaper (2006 and 2014): from episodic to thematic frames. ex æequo (34), 2016, pp.93108 [https://doi.org/10.22355/exaequo.2016.34.07 - acesso em 17 de janeiro de 2019]. 
cadernos pagu (59), 2020e205913 Por que o termo feminicídio incomoda tanto?

MAIA, Rousiley. Deliberation, the media and political talk. New York US, Hampton Press, 2012.

MAIA, Rousiley; ROSSINI, Patrícia G. C. OLIVEIRA, Vanessa V.; OLIVEIRA, Alicianne G. Sobre a importância de examinar diferentes ambientes online em estudosde deliberação. Opinião Pública (21), Campinas - SP, 2015, pp.490-513 [http://dx.doi.org/10.1590/1807$\underline{01912015212490}$ - acesso em 17 de janeiro de 2019].

MAIA, R.; CAL, D.; OLIVEIRA, V.; VIMEIRO, A.C.; HAUBER, G.; ROSSINI, P.; Deliberation Across a Space of Reasons: Assessing Epistemic Changes in Group Discussions, Human Communication Research (44), Oxford - UK, 2018, pp.399-426 [https://doi.org/10.1093/hcr/hqy007 - acesso em 17 de janeiro de 2019].

MARCUELLO-SERVÓS, Chaime, CORRADI, Consuelo; WEIL, Shalva; BOIRA, Santiago. Femicide: A social challenge. Current Sociology (64), 2016 , pp.967-974 [https://doi.org/10.1177/0011392116639358 - acesso em $17 \mathrm{de}$ janeiro de 2019].

MENDONÇA, Ricardo; AMARAL, Ernesto. Deliberação on-line em consultas públicas? $\mathrm{O}$ caso da Assembleia Legislativa de Minas Gerais. In: MENDONÇA, R.; SAMPAIO, R.; BARROS, S (orgs.). Deliberação Online no Brasil: entre iniciativas de democracia digital e redes sociais de conversação. Salvador - BA, EDUFBA, 2017, pp.82166 [http://repositorio.ufba.br/ri/handle/ri/19267 - acesso em 08 de outubro de 2020].

MIGUEL, Luís Felipe; BIROLI, Flávia. Mídia e representação política feminina: hipóteses de pesquisa. Opinião Pública (15). Campinas SP, 2009, pp.55-81.

[http://dx.doi.org/10.1590/S0104-62762009000100003 - acesso em 17 de janeiro de 2019].

MITOZO, Isabele; MARQUES, Jamil. Desafios da deliberação em iniciativas participativas on-line: um estudo do portal e-Democracia. In: MENDONÇA, R.; SAMPAIO, R.; BARROS, S (org.). Deliberação Online no Brasil: entre iniciativas de democracia digital e redes sociais de conversação. Salvador - BA, EDUFBA, 2017, pp.127-155 [http://repositorio.ufba.br/ri/handle/ri/19267 - acesso em 08 de outubro de 2020]. 
PAPACHARISSI, Zizi. Democracy online: civility, politeness, and the democratic potential of online political discussion groups. New media \&Society, 2004, pp. 259-283 [https://doi.org/10.1177/1461444804041444 - acesso em $17 \mathrm{de}$ janeiro de 2019].

PASINATO, Wânia. "Femicídios" e as mortes de mulheres no Brasil. cadernos pagu (37), Campinas - SP, 2011 [http://dx.doi.org/10.1590/S0104-83332011000200008 - acesso em 17 de janeiro de 2019].

PERULERO, Marisol Alcocer. "Prostitutas, infieles y drogadictas". juicios y prejuicios de género en la prensa sobre las victimas de feminicidio: el caso de Guerrero, Mexico. Antipoda. Revista de Antropología y Arqueología (20), Bogotá - Colômbia, 2014, pp.97-118 [http://dx.doi.org/10.7440/antipoda20.2014.05 - acesso em $17 \mathrm{de}$ janeiro de 2019].

POLLETTA, Francesca, LEE, John. Is Telling Stories Good for Democracy? Rhetoric in Public Deliberation after 9/11.American Sociological Review (71), Washington - US, 2006, pp.699-723 [https://www.jstor.org/stable/25472424 - acesso em 17 de janeiro de 2019].

SARMENTO, Rayza. Entre tempos e tensões: o debate mediado antes e depois da sanção da lei brasileira de combate à violência doméstica contra a mulher (2001 a 2012). Revista Feminismos (2), Salvador, $\mathrm{BA}$, 2014 [http://www.feminismos.neim.ufba.br/index.php/revista/article/view/11 $\underline{5}$ - acesso em 17 de janeiro de 2019].

SARMENTO, Rayza; MENDONÇA, Ricardo. Disrespect in online deliberation: inducing factors and democratic potentials. Revista De Ciência Política (36), Santiago - Chile, 2016, pp. 705-729 [https://scielo.conicyt.cl/scielo.php?script $=$ sci abstract\&pid $=$ S0718090X2016000300005\&lng $=\mathrm{pt} \& \mathrm{nrm}=\mathrm{iso \& t \operatorname {lng } = e n}$ - acesso em 08 de outubro de 2020].

SEGATO, Rita Laura. "Que és un feminicídio: notas para um debate emergente". Série Antropologia (401), Brasília - DF, 2006 [http://dan.unb.br/images/doc/Serie401empdf.pdf - acesso em 08 de outubro de 2020]. 
cadernos pagu (59), 2020e205913 Por que o termo feminicídio incomoda tanto?

STEINER, J. The Foundations of deliberative democracy. Empirical research and normative implications. Cambridge - UK, Cambridge University Press, 2012.

STEINER, J.; BÄCHTIGER, A.; SPÖRNDLI, M. and STEENBERGEN, M., Deliberative Politics in Action: analysing parliamentary discourse. Cambridge - UK, Cambridge University Press, 2004.

STEINER, Jürg; JARAMILLO, Maria Clara; MAIA, Rousiley; MAMELI, Simona. Deliberation across Deeply Divided Societies: Transformative Moments. Cambridge - UK, Cambridge University Press, 2017.

STROMER-GALLEY, J. Measuring deliberation's content: a coding scheme. Journal of Public Deliberation (3), 2007, pp.01-35 [https://www.publicdeliberation.net/ipd/vol3/iss1/art12 - acesso em 17 de janeiro de 2019].

STROMER-GALLEY, Jennifer; WICHOWSKI, Alexis. Political Discussion Online. In: CONSALVO, Mia; ESS, Charles (ed.). The Handbook of Internet Studies, Oxoford -UK, Willey- Blackwell, 2011, pp.168-187.

SUNSTEIN, Carl, Republic.com. Princeton - US, Princeton University Press, 2011.

WEIL, Shalva. Making femicide visible. Current Sociology (64), 2016, pp.1124-1137 [https://doi.org/10.1177/0011392115623602 - acesso em 17 de janeiro de 2019].

WOZNIAK, Jessica A.; MCCLOSKEY, Kathy A. Fact or fiction? Gender issues related to newspaper reports of intimate partner homicide. Violence Against Women (16), 2010, pp.934-952 [https://doi.org/10.1177/1077801210375977 - acesso em 17 de janeiro de 2019].

YOUNG, Iris Marion. Difference as a Resource for democratic communication. In: BOHMAN, Janmes; REHG, William (org.). Essays on reason and politics: Deliberative Democracy. Cambridge - UK, MIT Press, 1999, pp.383-406. 